\title{
What have we achieved? A reflection on the Census of Marine Life (COML)
}

\author{
Sven Thatje
}

Published online: 5 January 2011

(C) Springer-Verlag 2010

At the end of 2010, a decade long project of global collaborative research into the biodiversity and ecosystems of the oceans, known as the Census of Marine Life (COML), has come to an end. Over the ten year period, some 2,700 scientists from 80 nations, who became known as the Census community, discovered approximately 6,000 species new to science; 1,200 of these have been formally described, with many more to be described by taxonomists over the next few years, if not decades.

COML (www.coml.org) was an unprecedented international effort to assess the life thriving in our oceans, an environment that comprises $80 \%$ of Earth's biosphere. One result of the Census is that the estimated number of species known from our oceans has increased by approximately 20,000 , to around 250,000 species. Counting species alone was not the core aim of the research effort; of possibly much greater significance has been the cooperative international effort to bring together data on current and historical patterns in species distributions and abundances, and identify changes in response to anthropogenic and natural impacts. This effort has yielded a series of international databases that are now available to scientists and to the public at large (consult: www.coml.org). In times of globally observed changes in the environment, such baseline data are a crucial instrument for understanding and monitoring shifts in ecosystems, as well as in the abundance and distribution of populations and species. Changes within the sea are often much less obvious and more difficult to detect than those on land, and a lack of

\section{S. Thatje $(\square)$}

School of Ocean and Earth Science, University of Southampton, National Oceanography Centre, Southampton,

European Way,

Southampton SO14 3ZH, UK

e-mail: svth@noc.soton.ac.uk baseline data presents a major obstruction to scrutinizing the effects of anything, e.g. of anthropogenic impacts. Still, the question remains: where do we start? The shifting baseline syndrome is difficult to deal with. Our knowledge of species distribution and abundance shifts is probably best known from some fisheries dating back to early industrial explorations, but these often extend no more than 50 years into the past. This means that we are generally unable to set a true baseline before today's situation and prior to major anthropogenic impact, and that we actually compare different scales of altered ecological situations.

The question that arises when reviewing the COML is whether much if not most of the research activity would have taken place anyway? As an example, approximately 540 scientific expeditions to all oceans were associated with the COML, but many of these were funded through established national and international funding programmes. So, what was the real difference? From my personal point of view, the true value of the COML lies in the development of international collaboration, in knowledge transfer, and in the education of next-generation scientists, in seeking research synergies such as through shared use and development of new and often rare technologies essential to the exploration of the deep ocean, as well as in international standardisation of methodologies for research and for the management of data from research. There is also no doubt that some of the stunning imagery and the discoveries of many rather unexpected and weird new life forms attracted the attention of the public at large and increased their awareness of marine life.

One can only appreciate and value what is known and, unfortunately, without the use of electronic media experiencing the beauty of ocean life thriving at depth remains the privilege of a few. The need for public awareness is still often underestimated; without public support research in 
many cases remains unsuccessful in impacting political and management decisions.

However, what probably matters most is that the Census succeeded in crossing national and political borders by bringing together a community of people with a shared interest in the study and protection of life in the largest environment on Earth. If looked at as a kind of global experiment - and not only as a researchfocused one-the Census succeeded in achieving what most political decision makers still fail to accomplish: a globally shared interest in the environment, and a shared willingness to support its protection. We can only hope that the spin-off initiatives that are likely to result from the COML will be equally as successful as the first ten years, and will increasingly drive to accumulate sufficient knowledge to enable sustainable ocean management and the protection of the diversity of life in the sea. 